\title{
Informal Logic and its Implications for Philosophy
}

\section{Alec Fisher University of East Anglia}

\begin{abstract}
I take 'informal logic' to be the (descriptive and normative) study of 'real arguments' - arguments which are or have been used with the aim of convincing others of a point of view. I argue that the informal logic tradition thus conceived (i) lends strong support to something like Quine's view that our beliefs really support one another like the filaments in a spider's web-and thus that the traditional view that implication is an asymmetric relation is false; (ii) suggests that the classic division of arguments into deductive and inductive has distorted our thinking about the evaluation of real arguments; and (iii) implies that naturalised epistemology is on the right track.
\end{abstract}

Résumé: Selon la notion traditionnelle de la logique non formelle, celle-ci est l'étude descriptive et normative de vrais arguments, la fonction desquels est de convaincre les autres d'un point de vue. J'avance que cette notion a trois conséquences: (i) puisqu'elle soutient fortement un point de vue semblable à celui de Quine, selon lequel nos croyances s'appuient entre elles comme une toile d'araignée, l'idée traditionnelle selon laquelle l'implication est une relation asymmétrique est fausse; (ii) la division classique entre des arguments déductifs and inductifs a déformé notre façon d'évaluer des vrais arguments; (iii) l'épistémologie "naturalisée". est sur la bonne voie.

Keywords: informal logic, philosophy, Quine, web-of-belief, implication, deduction/ induction, reflective equilibrium, naturalised epistemology.

This paper considers some implications of informal logic for philosophy. I shail take the term "informal logic" to include much of what has developed under that name in the last 30 years though not all of it. As I see it, the best way to understand the term informal logic is that it studies "real arguments"-arguments which are or have been used with the aim of convincing others of a point of view-and it tries to understand and explain what makes such arguments succeed or fail in convincing their audiences in real contexts and what should do this; thus, it is partly a descriptive and partly a normative activity (we shall see the importance of this claim shortly). Given its general concern, it has been particularly interested in reflecting on fallacious reasoning (in context) and in saying what in general constitutes good reasoning (in context again), but a further and closely related objective has been to construct a general theory about how to interpret and evaluate real 
arguments which the "ordinary reasoner" could apply in handling such arguments in real contexts. This second objective explains why traditional predicate logic has relatively little to offer to the informal logic tradition, but also explains why, for example, a wonderfully insightful theory like Freeman's in Dialectics and The Macrostructure of Argument (1991) is flawed; it is so complex that it is frequently not applicable to real reasoning by the ordinary reasoner.

Given this background, I shall argue for three key implications of the informal logic tradition for philosophy. These are not of course logically deductive implications, but implications which are strongly suggested by work in the informal logic tradition. Firstly, it seems clear to me (and I think to many others) that what has emerged in this tradition lends strong support to something like Quine's view that our beliefs really support one another like the filaments in a spider's web - and thus that the traditional view that implication is an asymmetric relation is false. Closely related to this, it seems clear to me that the main philosophical casualty of the informal logic tradition is the old deductive/inductive divide; if you actually try to interpret and evaluate real argumentation using these tools, they often have a distorting effect on one's judgement (just as it would distort one's judgement to assume that all forms of Government must be either democracies or dictatorships), so they have to be abandoned in practical argumentation. A final implication is that naturalized epistemology is on the right track.

To take the first implication first, 1 do not mean to suggest that 1 can prove this claim to the sceptic. Quine's own arguments do not provide such proof (and those who believe that knowledge has foundations, that justified beliefs are, in the end, justified by being securely inferred from secure foundations, will continue to do so). Nicholas Everitt and l (1995) have presented philosophical arguments in favour of Quine's "web of belief," where Everitt first used the analogy of the crossword puzzle to explain the way beliefs can support each other (just as the answers to crossword puzzle clues do), so I am not engaged in repeating that exercise here; rather, 1 am claiming that if you work in the informal logic tradition and try to interpret and evaluate real reasoning in context you are likely to be struck by the way our beliefs are justified to the extend that they support and are supported by other beliefs we hold (and take to be justified). In his paper, "Logic and Argumentation," van Bentham articulates a similar picture; he says,

[The] rigid foundationalist view could lead, e.g., Gottlob Frege to think that the discovery of one single contradiction would bring all of mathematics down "like a house of cards". Real argument, however, is more like a piece of cloth: it still functions when a few strands have broken and become ragged. Its strength rather lies in a web of interconnections. (1995, p. 18)

In handling real reasoning in context, one is often struck by the need to go back and forth between premises and their justifications, inferences and their principles, background assumptions and their implications in ways which suggest mutual justification and support. 
It should come as no surprise that this is a relatively modest claim. There are few "knockdown" philosophical arguments over matters like this. It is rather that, as Rorty would describe it, a new way of thinking about argumentation is leaving a whole conception of justification on one side.

This is perhaps the point to mention that it seems to me that work in the informal logic tradition lends support to Goodman's view that principles of inference and our judgments about particular inferences are in "reflective equilibrium"; the principles inform our judgements about particular inferences, but may also be revised in the light of such judgements and that is all the justification one can have for accepting either. As Goodman puts it in Fact, Fiction and Forecast,

A rule is amended if it yields an inference we are unwilling to accept; an inference is rejected if it violates a rule we are unwilling to amend. The process of justification is the delicate one of making mutual adjustments between rules and accepted inferences; and in the agreement achieved lies the only justification needed for either. (1955, p. 64, emphasis in the original.)

Much of the work in fallacy theory has proceeded from a traditional view, only to discover some counter-examples, which have necessitated a revision of traditional rules. These revised rules then provide support for judgements in particular cases, until again they are challenged. The point is that there is no final certainty in all of this, mainly because different contexts can greatly influence what we accept as a good inference. To give a simple example, consider the argument,

(I) If Harry has swallowed a pound of arsenic, he will be dead. He is dead.

Therefore he swallowed a pound of arsenic.

This is clearly a fallacious argument and an example of the fallacy of affirming the consequent. However, here is an argument which has exactly the same form and would normally be taken to be a very strong argument,

(II) If the building burned to the ground, there will only be a pile of ashes.

There is only a pile of ashes.Therefore the building burned to the ground.

In both cases, what count as legitimate background assumptions determine the strength of the argument and the standard rule needs amending to deal with this.

To move to my second claim, that the traditional view that all reliable arguments are either deductive or inductive has to be abandoned. Though I am not centrally concerned to provide philosophical arguments against this view, Everitt and I have argued at length that problems arise with this distinction because it is not easy to identify the principles of deductive inference, and it is not easy to justify inductive inferences (see Everitt and Fisher, 1995). Furthermore, there is surely an implication of Quine's coherentism that has not been generally recognised. The argument goes like this:

If . . . we adopt a picture of our belief system on the model of the spider's web, where some propositions are more central to the system than others, and are less readily given up, whereas others are more peripheral. ... what are we to say about the inferential relations which 
exist between propositions in different parts of the web? They surely exhibit a similar variation, some being deeply embedded in our whole system of beliefs, and others being less so. The case for thinking so [is as follows]: to any piece of reasoning, there exists a corresponding hypothetical statement of the form 'If [the premises], then [the conclusion]', which we can call the principle of the argument. These principles can themselves be seen as propositions which may be believed or disbelieved. The principles of inference can thus be more or less deeply entrenched in the web of belief in the way that other believed propositions are. So they are best viewed as ranged on the same continuum rather than divided into the categories of deductive and inductive. Some of them are very close to the centre of our web and are ones which we should be very reluctant to give up (they are very close to what the old tradition called 'logical truths'). Others are more peripheral and are more readily given up (they are claims like "If Mary comes to the party, Joe won't', which might be based on the belief that each prefers to avoid the other).

It may even be that Quine himself recognised this. To quote him,

The totality of our so-called knowledge or beliefs, from the most casual matters of geography and history to the profoundest laws of atomic physics or even of pure mathematics and logic, is a man-made fabric which impinges on experience only along the edges.... Reevaluations of some statements entails reevaluations of others, because of their logical interconnectionsthe logical laws being in turn simply certain further statements of the system, certain further elements of the field. Having reevaluated one statement we must reevaluate some others, which may be statements logically connected with the first or may be statements of logical connections themselves. (1953, p.42, italics added)

These philosophical arguments aside it seems clear to me that there have long been substantial moves within the informal logic tradition against the "old" position. In his Challenge and Response (1971) Wellman argued that there are cases of good ethical reasoning which are neither deductive nor inductive, but are what he called "conductive" reasoning. "Conductive" reasoning occurs when someone draws a conclusion about some individual case from premises about the case, and without appeal to other cases (p.52). Several in the informal logic tradition, notably Govier (1987), have taken up this idea. Again, Wisdom's so-called Virginia lectures (1957), explaining what he called "case-by-case reasoning", have been taken up by informal logicians. Case-by-case reasoning occurs when, inferences are drawn concerning a particular case by using a kind of analogy from similar cases-and they are neither deductive nor inductive. Govier (1989) gives several kinds of argument where such case by case reasoning seems to be necessary, notably arguments from the presence of a property in a paradigm case to its occurrence in a less clear case, arguments which try to resolve borderline cases, and arguments using crite- 
ria which are not explicit enough to allow deductions. Again, in her Problems in Argument Analysis and Evaluation Govier has mounted substantial criticisms against The Great Divide (Ch. 3).

For those who wish to hold on to the distinction between deductive and inductive arguments, I suggest that they try to apply it to real reasoning and see whether it is a help or a hindrance. As an exercise one might look at some classic piece of reasoning and apply the distinction: take for example Galileo's argument that bodies of different mass must fall (under gravity) with the same acceleration. His argument looks to be a beautiful reductio ad absurdum of Aristotle's position (that heavier bodies fall faster), which proves deductively that bodies of different mass must fall with the same acceleration. Yet philosophers know that the evidence is crucial to deciding such an issue, so Galileo's argument cannot prove its conclusion deductively. What then does it do (since it is neither deductively valid nor inductively sound? In fact it is a wonderful "thought experiment" which shows that, given a particular "model" of how bodies function (the one we now all employ) bodies of different mass will accelerate under gravity at the same rate, but experience has to show whether the model applies. This does not make the argument deductively valid (within the model), but empirically irrelevant (because only the empirical evidence matters); rather it shows how, with the empirical evidence, our beliefs about physical objects hang together and explain and support one another. The empirical evidence alone (say, from dropping things off the Leaning Tower of Pisa) is not enough unless we can explain what is happening (i.e., fit it in with other things we believe). (For a further discussion of this example see Fisher, The Logic of Real Arguments, 1998, Ch. 6.)

This leads naturally to my third implication-that the philosophical arguments for naturalised epistemology resonate well with the informal logic tradition. To summarise, the argument here is that philosophers should sometimes leave the armchair and do some science too, that philosophy and science are not different kinds of activities - one being a priori, the other being empirical-but that they lie on a continuum, employing many similar techniques. There is no doubt that the informal logic tradition is essentially engaged in looking at the way we actually argue and persuade; it is a normative activity but it is an empirical one too. One of the striking things about handling real argumentation is how theory gets overturned by practice; for example, although it was long thought that ad hominem arguments were all fallacious, common usage has shown situations in which they are perfectly legitimate.

I am quite sure one cannot prove these claims to the satisfaction of a sceptic; I think that all one can say is, "Try the analysis and evaluation of real arguments by the methods used in the informal logic tradition (say, Scriven's method in Reasoning) and see whether they are adequate for the purpose in hand and even fruitful". Try it on a few examples, say Malthus's argument that the world will always contain many poor and starving people, or, if you prefer something more philosophical, Hume's argument against miracles. 
To consider Malthus's argument first; this famous "real" argument looks very impressive (and has persuaded many thinkers in the past 200 years). However, if we inspect the basic claims and the inferences based upon them, we find much that is questionable (as Engels realised long ago); its conclusion is neither deductively inferred from true premises nor inductively valid-and reconstructing it will not change this. To evaluate this historically important argument properly, one needs a plausible model which explains how the phenomena of population growth, economic growth, political power, etc., hang together-which fits the empirical evidence, but which also explains it in terms of other things we have good reason to believe. (For a first shot at doing this see Fisher, The Logic of Real Arguments, Ch. 3.)

Turning to our final example-Hume's argument against miracles-this is a fascinating argument mainly because it relies on assumptions about credibility, which is really fundamental to much of the informal logic tradition. Hume's argument will impress no-one who believes in miracles because of course it is less likely that Lazarus was raised from the dead than that someone made a mistake. On the other hand, if philosophers had dealt more systematically with the criteria for credible belief (as is a commonplace in the critical thinking tradition) Hume's argument would be greatly strengthened by being set in a context which contained explicit general beliefs about credibility, and would be seen to be the more reasonable for all that

To conclude. If you study real argumentation, in its context, one of the most striking things you notice, is what a lot is left out from the point of view of traditional philosophy. There are nearly always assumptions lying in the background, inferences which are neither deductively valid nor inductively sound (if there are such arguments), undefined concepts and unstated purposes. The more you try to fill in these gaps, the more yout tend to be struck by two facts. Firstly, in many contexts and for many purposes it is quite unnecessary to fill in the "gaps", since the argument can be seen to be adequate (or insufficient) to its purpose in that context without supplementation. Secondly, the more you try to fill in the gaps the more you see how rarely there is any way to construct the kind of secure, certain, well founded arguments so many philosophers still believe in and search for-and yet what one is left with may well be useful. 


\section{Bibliography}

Bentham, Johan van. (1995). "Logic and Argumentation," in Argumentation Illuminated. F. H. van Eemeren, R. Grootendorst, J. A. Blair and C. A. Willard, (eds.). Proceedings of the third ISSA conference on argumentation. (Vol. 1). Amsterdam: Sic Sat.

Everitt, Nicholas and Fisher, Alec. (1995). Modern Epistemology. New York, McGrawHill, Inc.

Fisher, Alec. (1988). The Logic of Real Arguments. Cambridge: Cambridge University Press.

Freeman, James. (1991). Dialectics and the Macrostructure of Argument. Berlin: Mouton de Gruyer.

Goodman, Nelson. (1955). Fact, Fiction and Forecast. New York: Bobbs-Merrill.

Govier, Trudy. (1987). Problems in Argument Analysis and Evaluation. Dordrecht: Foris Publications.

Govier, Trudy. (1989). "Analogies and Missing Premises," Informal Logic, XI.3, 141-152.

Scriven, Michael. (1976). Reasoning. New York: McGraw-Hill, Inc.

Quine, W. V. O. (1953). From a Logical Point of View. Cambridge. MA: Harvard University Press.

Wellman, Carl. (1971). Challenge and Response: Justification in Ethics. Carbondale, IL: University of lllinois Press.

Wisdom, John. (1957). "The Virginia Lectures." (Unpublished.)

Alec Fisher

The Old Rectory

Church Road, Booton

Norwich NR10 4NZ

United Kingdom 